\title{
DÉFICITS, GASTOS DO GOVERNO E A NÃO-ESTABILIDADE DA CARGA TRIBUTÁRIA NO CASO DO ESTADO DO RIO GRANDE DO SUL*
}

\author{
Liderau dos Santos Marques Junior ${ }^{\S}$
}

\begin{abstract}
RESUMO
A hipótese de estabilização da carga tributária (tax-smoothing hypothesis) implica: 1) a carga tributária ótima segue um passeio aleatório puro; 2) um superávit orçamentário igual ao valor presente esperado de variações nos gastos do governo. No presente artigo, são realizados testes de passeio aleatório da carga tributária para o período 1970-2002 e usa-se um modelo de vetores auto-regressivos para o período 1970-1997 no caso das finanças públicas do Estado do Rio Grande do Sul. Os testes rejeitam a hipótese de estabilização da carga tributária para o caso em estudo em ambos os períodos. Isto é, as evidências indicam que o governo estadual não se comportou como um tax-smoother.
\end{abstract}

Palavras-chave: tax-smoothing hypothesis, vetores auto-regressivos, Rio Grande do Sul.

\begin{abstract}
The tax-smoothing hypothesis implies that: 1) the optimal tax rate follows a pure random walk; 2) a budget surplus equal to the expected present value of changes in government expenditures. In this paper random walk tests of tax rate are performed for the period 1970-2002 and use a vector autoregression model to the period 1970-1997 in the case of the state of Rio Grande do Sul public finances. The tests reject the tax-smoothing hypothesis for the case in study for both periods. That is, the evidences show that the state government has not behaved as tax-smoother.
\end{abstract}

Key words: tax-smoothing hypothesis, vector autoregression, Rio Grande do Sul.

JEL classification: H3, H39.

\footnotetext{
* O autor agradece os valiosos comentários e observações de um parecerista anônimo.

$\S$ Doutor em Economia pelo PPGE-UFRGS. Professor pesquisador na Universidade de Passo Fundo (UPF). Endereço para contato: Endereço de contato: R. 24 de maio, 189/308. CEP 90050-180. Porto Alegre, RS. E-mail: liderau@hotmail.com. Recebido em agosto de 2005. Aprovado em fevereiro de 2007.
} 


\section{INTRODUÇÃO}

A teoria de Barro (1979) sobre como os governos administram a política fiscal pode ser assim resumida: dado que o governo visa minimizar os custos de distorção envolvidos na arrecadação de impostos - esses custos incluem transferência de recursos dos indivíduos para o governo e custos de coleta de impostos -, a dívida pública é usada para tornar regular a carga tributária ao longo do tempo; assim, se os gastos do governo se elevam, por uma razão qualquer, durante determinado período de tempo, ao invés de se aumentar os impostos, o governo se financia por meio da emissão de títulos públicos; passado o período de gastos elevados, os gastos voltam aos níveis normais e, mantida a carga tributária, são produzidos superávits orçamentários, o que possibilita o resgate da dívida pública gerada anteriormente. Por outro lado, quando o produto é transitoriamente elevado, a receita tributária fica acima do normal, gerando superávit orçamentário, que é utilizado para reduzir o endividamento público.

Os trabalhos que buscam testar a hipótese de estabilização da carga tributária podem ser divididos em duas linhas. A primeira linha adota como estratégia o teste de passeio aleatório, pois, num contexto estocástico, uma implicação da referida hipótese é de que a carga tributária ótima segue um passeio aleatório. Roubini e Sachs (1989) adotam esta linha ao trabalharem com uma amostra de 15 países da OECD. A segunda linha utiliza-se de um modelo de vetores auto-regressivos, VAR. Três artigos seguem esta linha: Huang e Lin (1993) estudam o caso dos Estados Unidos, Ghosh (1995) testa a hipótese para os casos do Canadá e Estados Unidos e Rocha (2001) analisa o caso do Brasil. Ghosh (1995), em particular, tem como foco a trajetória ótima do superávit orçamentário, não a trajetória observada da carga tributária. A hipótese de estabilização da carga tributária implica um superávit orçamentário igual ao valor presente esperado de variações nos gastos do governo. Por exemplo, se o governo espera um aumento de gastos em algum ponto no futuro, os impostos devem ser elevados imediatamente a fim de minimizar os custos de distorção provocados pela elevação de impostos quando de fato os gastos se elevarem.

O objetivo do presente artigo é o de testar a hipótese de estabilização da carga tributária no caso do Estado do Rio Grande do Sul utilizando-se de duas metodologias: o teste de passeio aleatório da carga tributária é realizado usando-se uma série entre 1970 e 2002, enquanto o método VAR é empregado para o período de 1970 a 1997. Os testes rejeitam a hipótese de estabilidade da carga tributária para ambos os períodos analisados. Em outras palavras, no caso em estudo, as evidências sugerem que o governo estadual não se comportou como um tax-smoother, ou seja, o governo não tratou de minimizar os custos associados à tributação.

O artigo está assim organizado: na segunda seção, apresentam-se a hipótese de estabilização da carga tributária, as implicações a serem testadas e o teste proposto por Ghosh (1995); na terceira seção, são apresentados os dados e os resultados empíricos; na quarta seção, tecem-se as considerações finais.

\section{O Modelo de Estabilização da Carga Tributária ${ }^{1}$}

Em Barro (1979, 1980, 1984 e 1989a) tem-se um mundo onde os impostos geram distorções; portanto, os déficits públicos são importantes porque alteram o timing dos impostos (por conseguinte, afetam os incentivos que as pessoas têm para trabalhar e produzir em diferentes períodos) e

1 A análise teórica a seguir tem como fontes Ghosh (1995) e Rocha (2001). Considera-se a carga tributária como sinônimo de alíquota média (ou, simplesmente, alíquota de um imposto). Em finanças públicas, a alíquota média é a relação entre o débito tributário e a base de cálculo. 
podem ser usados para manter a carga tributária constante ao longo do tempo, apesar de flutuações tanto nos gastos como na receita do governo. Tal regularidade da carga tributária implica déficits públicos, quando os gastos do governo são inusitadamente elevados, e superávits, quando os gastos são anormalmente baixos.

Considerando-se uma economia fechada e na qual um governo compra a quantidade $G_{t}$ de bens dos produtores privados, os gastos do governo são usados na oferta de um fluxo de serviços públicos para as famílias e firmas. O governo financia essas compras por meio de duas fontes: arrecadação tributária corrente e emissão de dívida pública. A arrecadação tributária em cada período é denotada por $T_{t}$ e a renda real agregada (PIB real), por $Y_{t}$. Os impostos que o governo arrecada geram distorções, ou seja, não são lump sum - um exemplo deste tipo de tributo é o imposto de renda. O estoque de dívida pública ao final do período $t$ é denotado por $B_{t}$. A maturidade da dívida pública é de um período e os valores dos títulos emitidos são a par. Tanto $G_{t} \operatorname{como} Y_{t}$ são tratadas como variáveis exógenas. Valores futuros de $G_{t}$ e de outras variáveis exógenas são conhecidos com certeza.

Nessa economia, os déficits públicos são usados para tornar regular a carga tributária ao longo do tempo. Assim, se os gastos do governo se elevam por uma razão qualquer durante determinado período de tempo, ao invés de se aumentar os impostos, são gerados déficits públicos financiados por meio de dívida pública; passado o período de gastos elevados, os gastos voltam aos níveis normais e, mantida a carga tributária, produzem-se superávits orçamentários. ${ }^{2}$ Esta política visa minimizar os custos de distorção envolvidos na arrecadação de impostos, os quais incluem transferência de recursos dos indivíduos para o governo e custos de coleta de impostos.

Para se obter a trajetória ótima da carga tributária ao longo do tempo, assume-se que a função objetivo do governo é dada por: ${ }^{3}$

$$
V=\operatorname{Max}-\frac{1}{2} \sum_{t=0}^{\infty} \beta^{t} \tau_{t}^{2}
$$

onde $V$ é o valor presente dos custos de distorção, $\tau_{t}=T_{t} / Y_{t}$ é a carga tributária (ou a alíquota média do imposto), $\beta$ é a taxa de desconto subjetiva do governo e $0<\beta<1$. A taxa de desconto representa as preferências do governo.

A restrição orçamentária do governo pode ser assim reescrita:

$$
B_{t+1}=(1+r) B_{t}+G_{t}-\tau_{t} Y_{t}
$$

onde $r$, a taxa de juros real, é suposta constante. Supõe-se que a trajetória dos gastos do governo é exógena.

Dividindo-se (2) por $Y_{t}$, obtém-se:

$$
(1+n) b_{t+1}=(1+r) b_{t}+g_{t}-\tau_{t}
$$

onde $n$, a taxa de crescimento do produto, é também suposta constante.

2 Nessa mesma situação, a política de orçamento equilibrado implicaria aumento de impostos durante o período de gastos elevados e diminuição das alíquotas médias quando os gastos retornassem aos níveis normais.

3 A função (1) assume que a função dos custos de distorção é quadrática. A função geral dos custos é dada por $C_{t}=F\left(T_{t}, Y_{t}\right)=f\left(\tau_{t}\right) Y_{t}$, onde $C$ são os custos de coleta de impostos, $T$ é a receita tributária e $Y$, o produto agregado da economia. A função geral aparece em Barro (1979), Huang e Lin (1993) e Romer (2001). 
Fazendo substituições recursivas em (2) e (3), obtém-se a restrição orçamentária intertemporal do governo:

$$
\sum_{i=0}^{\infty} \frac{G_{t+i}}{(1+r)^{i}}=\sum_{i=0}^{\infty} \frac{\tau_{t+i} Y_{t+i}}{(1+r)^{i}}-(1+r) B_{t}
$$

$\mathrm{ou}$

$$
\sum_{i=0}^{\infty} g_{t+i}\left[\frac{(1+n)}{(1+r)}\right]^{i}=\sum_{i=0}^{\infty} \tau_{t+i}\left[\frac{(1+n)}{(1+r)}\right]^{i}-(1+r) b_{t}
$$

Substituindo-se (3) na (1), chega-se ao problema do governo de minimizar o valor presente dos custos de distorção sem restrição:

$$
V=-\frac{1}{2} \sum_{t=0}^{\infty} \beta^{t}\left[(1+r) b_{t}+g_{t}-(1+n) b_{t+1}\right]^{2}
$$

Conforme a abordagem da equação de Euler, a condição de otimização propõe que uma pequena redução da carga tributária em $t, \Delta \tau$, é igual ao aumento na carga no próximo período, $\frac{1}{\beta} \Delta \tau$. Esta mudança não altera o valor presente dos custos associados à tributação. Sucintamente, a condição de otimização pode ser assim expressa: $\frac{d C_{t}}{d b_{t}}=\frac{1}{\beta} \frac{d C_{t+1}}{d b_{t+1}}$, ou seja, o benefício marginal de uma redução da carga tributária em $t$ é igual ao custo marginal de uma elevação da carga em $t+1$. Do problema do governo, tem-se que o benefício marginal em $t$ é dado por $-\beta^{t} \tau_{t}(1+r)$, enquanto o custo marginal em $t+1$ é igual a $-\beta^{t+1} \tau_{t+1}(1+r) \frac{1}{\beta}$. Assim, a condição para que o benefício marginal seja igual ao custo marginal é a de que $\tau_{t}=\tau_{t+1}$, isto é, a carga tributária é mantida constante entre os períodos $t$ e $t+1$. $^{4}$ Em outras palavras, o valor presente dos custos de distorção é mantido constante porque um aumento de $b_{t}$, em função de uma redução da alíquota do imposto em $t$, é exatamente igual à redução de $b_{t+1}$, em razão do aumento da alíquota do imposto em $t+1$. A política ótima que minimiza os custos de distorção provocados pela arrecadação de impostos é a de manter constante a carga tributária, $\tau^{c}$, ao longo de todos os períodos futuros.

Assim, substituindo-se $\tau^{c}$ na equação (4b), chega-se ao seguinte resultado:

$$
\tau^{c}=(r-n) b_{t}+\left(\frac{r-n}{1+r}\right) \sum_{i=0}^{\infty} g_{t+i}\left[\frac{(1+n)}{(1+r)}\right]^{i}
$$

isto é, a carga tributária ótima é igual ao gasto permanente mais os juros pagos sobre a dívida pública.

4 Essa linha de raciocínio segue os passos de Romer (2001, p. 543).

5 Roubini e Sachs (1989) chamam o segundo termo do lado direito da equação (5) de gasto permanente. 
Substituindo-se (5) na equação (3), obtém-se a trajetória ótima da relação dívida pública e PIB (ou da razão déficit público/PIB), correspondente à trajetória ótima da carga tributária:

$$
b_{t+1}-b_{t}=\frac{1}{1+n}\left\{g_{t}-\left(\frac{r-n}{1+r}\right) \sum_{i=0}^{\infty} g_{t+i}\left[\frac{(1+n)}{(1+r)}\right]^{i}\right\}
$$

Portanto, a razão dívida/PIB é função da diferença entre os gastos temporários, $g_{t}$, e os gastos permanentes do governo. Então, quando os gastos temporários do governo são maiores do que os gastos permanentes, $b$ cresce; ao contrário, quando os gastos temporários ficam abaixo dos gastos permanentes, $b$ decresce; por último, quando há igualdade entre gastos temporários e permanentes, a razão dívida/PIB é constante.

No contexto estocástico, a hipótese de estabilização da alíquota média do imposto de renda equivale a afirmar que a alíquota apresenta um comportamento semelhante ao de um passeio aleatório. Daí se tem duas implicações: a primeira, considerando que as trajetórias de $G_{t}$ e $Y_{t}$, assim como das demais variáveis, são incertas, novas informações sobre as trajetórias de $G_{t}$ e $Y_{t}$ implicam mudanças na alíquota do imposto, todavia, dado o conjunto de informação do período anterior, o sinal e a magnitude de tais mudanças entre dois períodos são imprevisíveis; a segunda, não existe uma meta para a razão dívida/PIB, pois a sua evolução depende das expectativas em relação às trajetórias $G_{t}$ e $Y_{t}$.

A partir de agora, serão demonstradas as afirmações acima, tomando-se como base o modelo proposto por Ghosh (1995). Para se obter a trajetória ótima da alíquota média do imposto de renda (ou da carga tributária) ao longo do tempo, assume-se que a função objetivo do governo é dada por:

$$
V=\operatorname{Max}-\frac{1}{2} \sum_{t=0}^{\infty} \beta^{t} E_{t}\left[\tau_{t}^{2}\right]
$$

onde $E_{t}$ é o valor esperado condicionado ao conjunto de informação do governo no período $t$.

No período $t$, o problema do governo é o de minimizar o valor presente esperado dos custos de distorção sem restrição:

$$
V=-\frac{1}{2} \sum_{t=0}^{\infty} \beta^{t} E_{t}\left[(1+r) b_{t}+g_{t}-(1+n) b_{t+1}\right]^{2}
$$

Aplicando-se a abordagem da equação de Euler, considere uma pequena redução da carga tributária em $t, \Delta \tau$, em relação ao valor planejado para $t$, dadas as informações disponíveis. De modo a satisfazer a restrição orçamentária, a carga tributária no período $t+1$ se eleva no montante $\frac{1}{\beta} \Delta \tau$ em relação ao valor que seria obtido, dadas as informações para aquele período. Se o governo é um otimizador, esta mudança não altera o valor presente esperado dos custos de distorção associados à tributação. Sucintamente, a condição de otimização pode ser assim expressa: $\frac{d C_{t}}{d b_{t}}=\frac{1}{\beta} E_{t}\left[\frac{d C_{t+1}}{d b_{t+1}}\right]$, ou seja, não se pode prever mudanças nos custos de distorção marginais associados à tributação. Do problema do governo, obtém-se a seguinte equação: $-\beta^{t} \tau_{t}(1+r)=-\beta^{t+1} E_{t}\left[\tau_{t+1}\right](1+r) \frac{1}{\beta}$. Essa 
igualdade se verifica se $\tau_{\mathrm{t}}=E_{t}\left[\tau_{\mathrm{t}+1}\right]$. ${ }^{6}$ Isto é, a carga tributária ótima segue um passeio aleatório puro (sem drift e sem tendência temporal). Em outras palavras, num contexto estocástico, a carga tributária corrente é a previsão ótima da carga tributária no futuro. Intuitivamente, é um resultado ótimo a carga tributária seguir um processo passeio aleatório puro, pois, se houver um choque, este será incorporado a carga tornando-se permanente. Por exemplo, um aumento de $g_{t}$ implicará a elevação permanente da carga; já uma redução de $g_{t}$ redundará em uma diminuição permanente da carga tributária. Evidentemente, a elevação (ou a redução) da carga é permanente enquanto não ocorrer um novo choque.

A restrição orçamentária intertemporal pode ser reescrita da seguinte maneira:

$$
E_{t}\left\{\sum_{i=0}^{\infty} g_{t+i}\left[\frac{(1+n)}{(1+r)}\right]^{i}\right\}=E_{t}\left\{\sum_{i=0}^{\infty} \tau_{t+i}\left[\frac{(1+n)}{(1+r)}\right]^{i}-(1+r) b_{t}\right\}
$$

Substituindo-se $\tau_{t}=E_{t}\left[\tau_{t+1}\right]$ na equação acima, chega-se à alíquota ótima em cada período:

$$
\tau_{t}=(r-n) b_{t}+\left(\frac{r-n}{1+r}\right) \sum_{i=0}^{\infty}\left[\frac{(1+n)}{(1+r)}\right]^{i} E_{t}\left[g_{t+i}\right]
$$

Portanto, a carga tributária ótima em cada período de tempo é igual aos juros pagos mais o valor presente esperado dos gastos.

A implicação que o sinal e a magnitude da mudança na alíquota do imposto entre dois períodos são imprevisíveis, dado o conjunto de informação do período anterior, ou seja, que a carga tributária (otimamente estabelecida) segue um passeio aleatório puro, supondo-se $b_{t}=b_{t-1}$, é expressa por:

$\tau_{t}-\tau_{t-1}=\left(\frac{r-n}{1+r}\right) \sum_{i=0}^{\infty}\left[\frac{(1+n)}{(1+r)}\right]^{i} E_{t}\left[g_{t+i}\right]-\left(\frac{r-n}{1+r}\right) \sum_{i=0}^{\infty}\left[\frac{(1+n)}{(1+r)}\right]^{i} E_{t-1}\left[g_{t+i}\right]$

ou

$\tau_{t}-\tau_{t-1}=\left(\frac{r-n}{1+r}\right)\left\{\sum_{i=0}^{\infty}\left[\frac{(1+n)}{(1+r)}\right]^{i}\left[E_{t}\left(g_{t+i}\right)-E_{t-1}\left(g_{t+i}\right)\right]\right\}$

Dado que o lado direito de (9b) é um erro de expectativas, deve ser imprevisível tomando-se como base a informação disponível no período t-1 ou anterior. Segundo Ghosh (1995), a equação (9b) estabelece que a carga tributária deveria seguir um passeio aleatório.

Ghosh (1995) define o superávit público como $\sup _{t} \equiv(1+n)\left(b_{t}-b_{t+1}\right)$. De (3) tem-se que $\sup _{t}=\tau_{t}-g_{t}-(r-n) b_{t}$ e, usando-se a (8), obtém-se: ${ }^{8}$

6 Essa linha de raciocínio segue os passos de Romer (2001, p. 544). Roubini e Sachs (1989, p. 911) afirmam que, em igual contexto, a carga tributária ótima segue um processo passeio aleatório com drift.

7 A equação (8) assume, implicitamente, que o único motivo que leva o governo a gerar déficits orçamentários é o de minimizar os custos de distorção; portanto, em períodos de gastos elevados, há crescimento da dívida pública, que, por sua vez, será resgatada em períodos de menores gastos. O motivo tax tilting - governo aloca o peso da tributação sobre o presente ou sobre o futuro - é considerado por Ghosh (1995) ao se multiplicar o lado direito de (8) por $\theta=[(1-(R / \beta) \mathrm{R} /(1-R)]$ onde $R \equiv(1+n) /(1+r)$. Outro ponto salientado por Ghosh (1995) é o de que existe diferença entre a taxa de juros efetiva, $(1+r) /(1+n)$, e a taxa de juros de mercado, $(1+r)$. Se a taxa de crescimento econômico é positiva, a taxa de juros efetiva é menor do que a taxa de juros de mercado.

8 Note-se que $\sup _{t}=\mathrm{SUP}_{t} / Y_{t}=-\mathrm{DEF}_{t} / Y_{t}$. 


$$
\sup _{t}=\left\{\left(\frac{r-n}{1+r}\right) \sum_{i=0}^{\infty}\left[\frac{(1+n)}{(1+r)}\right]^{i} E_{t}\left[g_{t+i}\right]-g_{t}\right\}
$$

ou

$$
\sup _{t}=\sum_{j=1}^{\infty}\left[\frac{(1+n)}{(1+r)}\right]^{j} E_{t}\left[\Delta g_{t+i}\right]
$$

onde $\Delta g_{t+j} \equiv g_{t+j}-g_{t+j-1}$.

Ghosh (1995) observa que a equação (10b) formaliza a idéia de que, na hipótese de estabilização da carga tributária, os superávits públicos incorporam mudanças temporárias nos gastos do governo. Em outras palavras, (10b) propõe que o superávit em cada período $t$ é igual ao valor presente esperado de variações nos gastos. Assim, dado um montante de gastos em $t$, supondo-se que o governo espere uma elevação dos gastos no futuro, como seu objetivo é minimizar os custos de distorção, a estratégia ótima é a de elevar os impostos imediatamente. Como a receita tributária se eleva antes do aumento dos gastos, obtém-se um superávit público maior do que aquele que seria gerado sem a expectativa de elevação dos gastos.

Para Ghosh (1995), a equação (10b) incorpora todas as implicações da carga tributária ótima intertemporalmente; portanto, proporciona um caminho adequado para testar a hipótese de estabilização da carga tributária. Em resumo, compara o superávit público real, definido como $\sup _{t}=\tau_{t}-g_{t}-(r-n) b_{t}$, com o superávit público ótimo, $\sup _{t}^{*}=\sum_{j=1}^{\infty}\left[\frac{(1+n)}{(1+r)}\right]^{j} E_{t}\left[\Delta g_{t+i}\right]$.

O primeiro passo é gerar o lado direito do superávit público ótimo. Diante dessa dificuldade, Ghosh (1995) propõe a seguinte hipótese nula: como o governo tem mais informação sobre a trajetória dos gastos futuros do que o que está contido nos valores defasados de $\Delta g_{t}$, o superávit público conterá toda essa informação adicional e, portanto, causará $\Delta g_{t}$ no sentido de Granger.

Para se testar a hipótese acima, Ghosh (1995) propõe um modelo VAR irrestrito em $\Delta g$ e sup:

$$
\left[\begin{array}{l}
\Delta g_{t} \\
\sup _{t}
\end{array}\right]=\left[\begin{array}{l}
a_{1} a_{2} \\
a_{3} a_{4}
\end{array}\right]\left[\begin{array}{l}
\Delta g_{t-1} \\
\sup _{t-1}
\end{array}\right]+\varepsilon_{t}
$$

ou $z_{t}=A z_{t-1}+U_{t}$, onde $z=\left[\Delta g_{t} \sup _{t}\right]$ ', $A$ é matriz de transição do VAR e $U$ é o vetor de erros (ruído branco). Um VAR de primeira ordem é utilizado porque uma defasagem é a que melhor se ajusta aos dados do Rio Grande do Sul. A previsão ótima de $z_{t}, k$ períodos à frente, é simplesmente $E_{t} z_{t+k}=A^{k} z_{t}$ para $k \geq 1$. Portanto, (10b) implica

$$
[01] z_{t}=\sum_{i=1}^{\infty} R^{i} A^{i}[10] z_{t}
$$

Desde que $\Delta g$ e sup sejam séries estacionárias, a soma infinita em (12) converge para:

$$
\begin{aligned}
& \sup _{t}^{*}=[10] R A[I-R A]^{-1} z_{t} \\
& \equiv \Lambda z_{t}=\lambda_{1} \Delta g_{t}+\lambda_{2} \sup _{t}
\end{aligned}
$$


Isso posto, Ghosh (1995) afirma o seguinte: se a hipótese nula é correta, o coeficiente $\lambda_{1}$ deve ser igual a zero e o coeficiente $\lambda_{2}$ deve ser igual a 1 .

Até agora, supôs-se que $\mathrm{R}=\beta$, isto é, que $\theta=1$. Quando $\mathrm{R}>\beta$, o governo tax-tilting, isto é, desloca os impostos do presente para o futuro gerando grandes déficits; neste caso, $\theta<1$. Quando $\mathrm{R}<\beta$, ocorre o inverso, e $\theta>1$. Então, quando $\theta \neq 1$, o superávit público é dado por:

$$
\sup _{t}=\left(\frac{1}{\theta}\right) \tau_{t}-\left[g_{t}+(r-n) b_{t}\right]
$$

Ghosh (1995) conclui: desde que $\tau_{\mathrm{t}}$ e $\left[g_{t}+(r-n) b_{t}\right]$ sejam I(1), a equação (15) define uma regressão de cointegração; assim, $(1 / \theta)$ pode ser estimado regredindo-se $\left[g_{t}+(r-n) b_{t}\right]$ sobre $\tau_{t}$ ou vice-versa.

\section{NO CASO DO ESTADO DO RIO GRANDE DO SUL, A SUA CARGA TRIBUTÁRIA É ESTÁ- VEL AO LONGO DO TEMPO?}

\section{Os dados}

O objeto de estudo é a Administração Direta do Estado do Rio Grande do Sul. Os dados originais da despesa total (incluindo o serviço da dívida), da despesa total menos o serviço da dívida, da dívida pública total e da receita tributária (arrecadada) têm como fontes o Balanço Geral do Estado e a publicação intitulada Finanças do Estado, de diversos anos. O serviço da dívida é a soma de juros e encargos da dívida mais a amortização da dívida pública. A fonte dos dados do PIB estadual é a Fundação de Economia e Estatística (FEE). Issler e Lima (1997) chamam a atenção para o seguinte detalhe: a despesa total inclui pagamentos de juros nominais sobre a dívida pública; portanto, a série observada difere da série teórica que inclui pagamento de juros reais. É importante ressaltar ainda que a série do PIB estadual de 1970 a 2002 é uma combinação de duas séries: uma que parte de 1970 e vai até 1985 e outra de 1985 a 2002. Segundo o Núcleo de Contas Regionais da FEE, houve uma mudança de metodologia no cálculo do PIB. A série do PIB - ver Tabela 7 do Anexo - foi montada tomando-se a série de 1970 até 1985 e a série de 1986 a 2002.

Todas as variáveis foram convertidas para reais $(\mathrm{R} \$)$; após a conversão, foram obtidas as relações: dívida pública/PIB, receita tributária/PIB, $\tau_{t}$, despesa total/PIB, $g^{*}$, despesa total menos serviço da dívida/PIB, $g_{t}$, e superávit público/PIB, $\sup _{\mathrm{t}}=\Delta b_{t}$, onde $b$ é a dívida mobiliária estadual. Os dados são anuais. Os dados da dívida pública/PIB e da carga tributária compreendem o período de 1970 a 1997; o restante dos dados referem-se ao período de 1970 a 2002. Os dados encontram-se no Anexo. O software utilizado foi o Eviews (versão 3.0).

\section{Resultados empíricos}

O modelo de estabilização da carga tributária propõe que a relação dívida/produto decresce durante os anos de gastos normais e de crescimento econômico e cresce nos períodos de gastos temporariamente elevados ou de recessão econômica.

9 Com base em Enders (1995), Pastore (1995) e Pereira (1998). 
No caso do Estado do Rio Grande do Sul, o que se observa no Gráfico 1 é a existência de um crônico crescimento da relação dívida pública/PIB. Entre 1970 e 1980 a relação dívida/PIB é praticamente estável, todavia, no começo da década de 1980, a trajetória da relação dívida/PIB assume uma tendência de crescimento; entre 1986 e 1994, a relação atinge os maiores níveis e, após 1994, retoma a tendência de crescimento. Portanto, esse comportamento da relação dívida pública/PIB é um primeiro indício de que a hipótese de estabilização da carga tributária não se verifica no caso do Rio Grande do Sul.

\section{Gráfico 1 - Evolução da relação dívida pública/PIB (Administração Direta) do Estado do Rio Grande do Sul (1970-2002)}

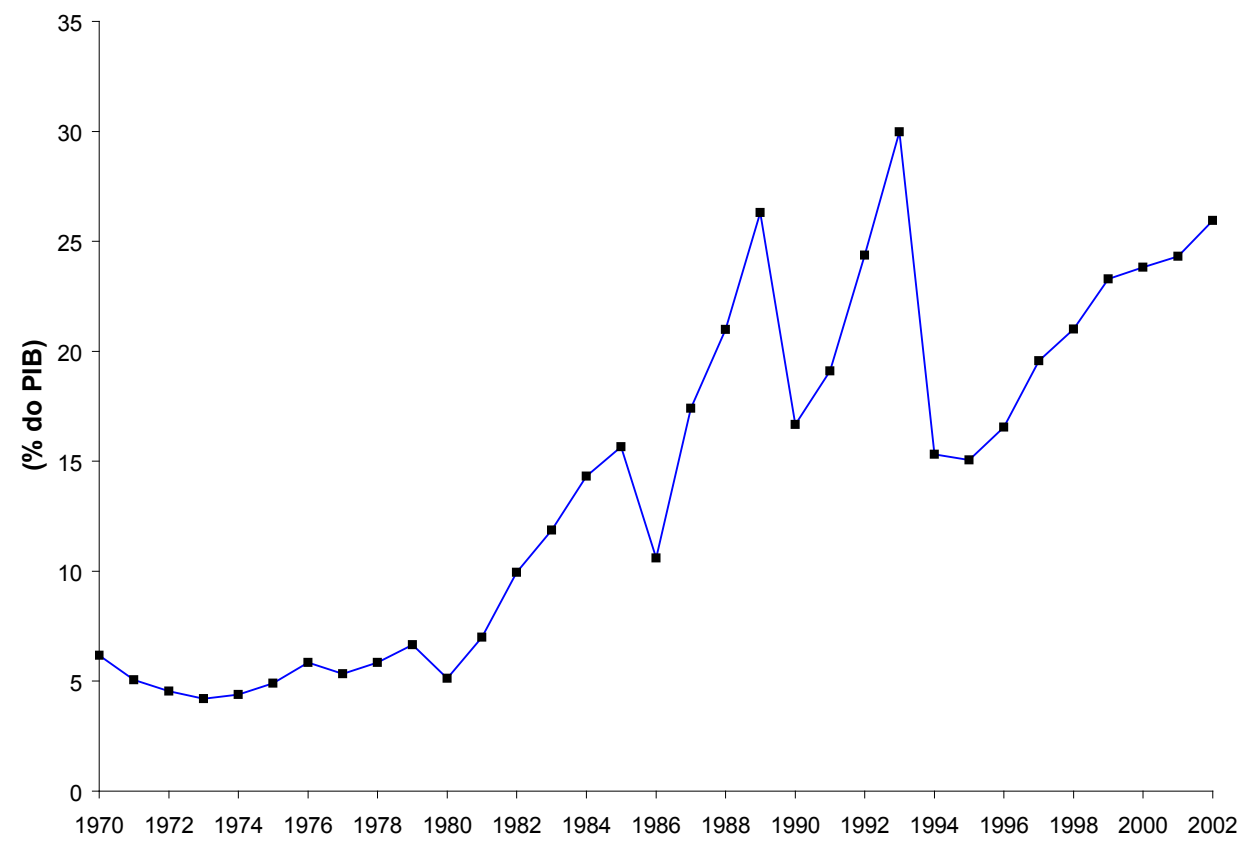

Fonte: Tabela 8 do Anexo.

Definiu-se carga tributária como a relação entre a receita tributária estadual (impostos mais taxas) e o PIB estadual. ${ }^{10}$ Entre os impostos arrecadados pelo Estado, a principal fonte de financiamento é o imposto sobre circulação de mercadorias e serviços (ICMS). Aliás, o ICMS é o principal tributo do Brasil, respondendo, segundo Bordin (2003), por quase um quarto da receita tributária nacional. ${ }^{11}$

No Gráfico 2, observa-se uma tendência de queda da carga tributária no período 1971 a 1980; no período 1981 a 1996, não se tem uma tendência clara; já, no período final, 1997 a 2001, a tendência é de crescimento da carga tributária. De fato, o comportamento da carga tributária se assemelha a uma parábola. Em suma, no período como um todo, a série da carga tributária apresenta um comportamento errático, ou seja, a carga não tende para uma média de longo prazo.

10 Conforme Bordin (2002), essa é a definição comumente utilizada por muitos órgãos internacionais, tais como o FMI e o Banco Mundial. No entanto, salienta que a carga tributária no Brasil é medida pela relação entre a receita tributária total (União, Estados e Municípios) e o PIB nacional, sendo que a receita tributária total engloba os tributos (impostos, taxas e contribuições de melhoria) e as contribuições sociais que financiam o sistema de Seguridade Social do país.

11 Para uma caracterização do ICMS (evolução histórica, aspectos institucionais, etc.), ver Schwengber e Ribeiro (2000). 
Este comportamento permite afirmar que a média da série não é constante. Isto leva a suspeitar da presença de raiz unitária na trajetória da carga tributária.

\section{Gráfico 2 - Evolução da carga tributária (1970-2002)}

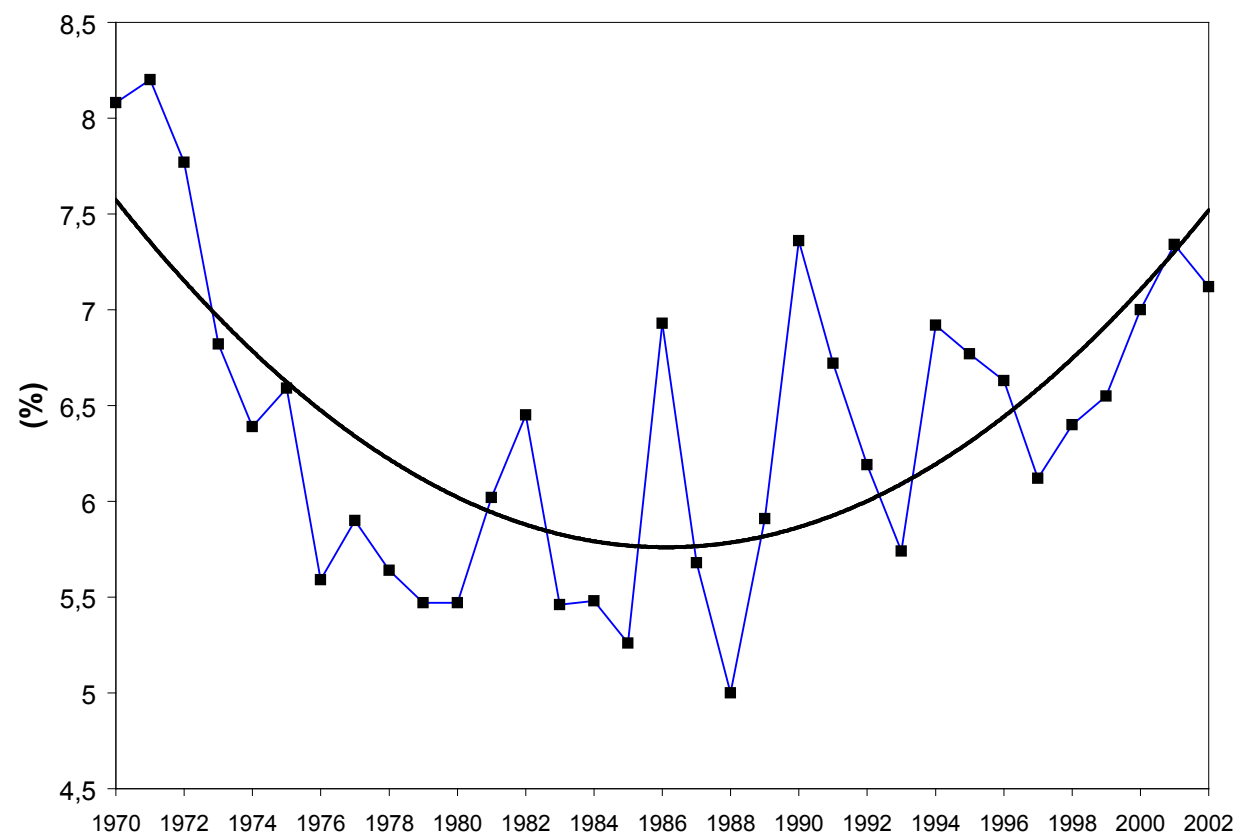

Fonte: Tabela 7 do Anexo.

A hipótese de que a carga tributária, no caso do Estado do Rio Grande do Sul, segue um passeio aleatório puro é testada utilizando-se o teste de raiz unitária de Dickey-Fuller aumentado. ${ }^{12} \mathrm{O}$ teste é realizado a partir da seguinte regressão:

$$
\Delta \tau_{t}=a_{0}+\gamma \tau_{t-1}+a_{2} t+\sum_{i=1}^{p} \beta_{i} \Delta \tau_{t-i}+\varepsilon_{t}
$$

onde $p$ é o número de defasagens, $\varepsilon$ é o erro (ruído branco), $\tau$ é a carga tributária e $t$, a tendência linear.

Optou-se pelo teste de raiz unitária de Dickey-Fuller aumentado porque os correlogramas dos resíduos, nos testes de raiz unitária de Dickey-Fuller comuns, indicaram a existência de autocorrelação nos resíduos.

Na Tabela 1, têm-se os resultados dos testes de Dickey-Fuller aumentado para a série da carga tributária.

12 Roubini e Sachs (1989) testam a hipótese de estabilização da carga tributária para 15 países da OECD rodando uma regressão simples para cada um, tendo como variável dependente a variação na carga tributária e, como variável independente, uma constante. Rocha (2001) testa a hipótese de estabilização da carga tributária (tax smoothing hypothesis) para o Brasil utilizando um modelo de vetores auto-regressivos. 
Tabela 1 - Testes de raiz unitária Dickey-Fuller aumentado ${ }^{13}$

\begin{tabular}{lrrr}
\hline & $\begin{array}{r}\text { Regressão com constante e } \\
\text { tendência }\end{array}$ & $\begin{array}{r}\text { Regressão com constante e } \\
\text { sem tendência }\end{array}$ & $\begin{array}{c}\text { Regressão sem tendência e } \\
\text { constante (passeio aleatório } \\
\text { puro) }\end{array}$ \\
\hline Constante & 3,039374 & 2,961430 & \\
& $(2,776864)$ & $(2,101135)$ & $-0,008007$ \\
$\tau_{t-1}$ & $-0,63495$ & $-0,480359$ & $(-0,426738)$ \\
$T$ & $(-3,545263)$ & $(-2,130234)$ & \\
& 0,048041 & & $-0,322228$ \\
$\Delta \tau_{t-1}$ & $(4,099842)$ & & $(-1,840585)$ \\
$\Delta \tau_{t-2}$ & $-0,183500$ & $-0,059446$ & $-0,396250$ \\
$\Delta \tau_{t-3}$ & $(-1,125051)$ & $(-0,287993)$ & $(-2,358267)$ \\
SRQ & $-0,354090$ & $-0,226368$ & $-0,398465$ \\
AIC & $(-2,510890)$ & $(-1,277937)$ & $(-2,255002)$ \\
SBC & $-0,486207$ & $-0,320153$ & 9,834281 \\
P & $(-3,523602)$ & $(-1,884533)$ & 2,03 \\
N & 4,799097 & 8,306341 & 2,22 \\
\hline
\end{tabular}

Notas: 1) SRQ (soma dos resíduos ao quadrado), AIC (critério informação Akaike) e SBC (critério bayesiano Schwartz); 2) as estatísticas $t$ estão entre parênteses.

Os testes da presença de uma raiz unitária são apresentados na Tabela 2 e consistem no teste de significância do coeficiente $\gamma$, utilizando-se os valores críticos de Mackinnon:

Tabela 2 - Testes de raiz unitária Dickey-Fuller aumentado

\begin{tabular}{lccc}
\hline & $\begin{array}{c}\text { Regressão com constante e } \\
\text { tendência }\end{array}$ & $\begin{array}{c}\text { Regressão com constante } \\
\text { e sem tendência }\end{array}$ & $\begin{array}{c}\text { Regressão sem tendência e } \\
\text { constante (passeio aleatório puro) }\end{array}$ \\
\hline Estatística de Dickey-Fuller & $-3,545263$ & $-2,130234$ & $-0,426738$ \\
Valores críticos de Mackinnon & & & \\
$1 \%$ & $-4,3082$ & $-3,6752$ & $-2,6453$ \\
$5 \%$ & $-3,5731$ & $-2,9665$ & $-1,9530$ \\
$10 \%$ & $-3,2203$ & $-2,6220$ & $-1,6218$ \\
\hline
\end{tabular}

Na regressão com constante e tendência, não é possível rejeitar a hipótese nula de que $\gamma=0$ aos níveis de significância de $1 \%$ e $5 \%$. Com relação às demais regressões, a hipótese nula de que $\gamma=0$ é aceita aos três níveis de significância. Portanto, há fortes indícios de não-estacionariedade da carga tributária, isto é, de presença de raiz unitária.

Dada a existência de uma raiz unitária, propõe-se o seguinte teste para a presença de tendência linear. Na regressão com tendência e constante, a estatística $t$, para a hipótese nula, $a_{2}=0$, é 4,099842. Os valores críticos apropriados são dados pela estatística $\tau_{\beta \tau}$ de Dickey-Fuller. Consi-

13 Para a escolha de $p=3$, adotou-se o procedimento de Campbell e Perron (1991), cuja apresentação pode ser encontrada em (Pereira, 1998, p. 45). Nos testes realizados, o número inicial de termos defasados foi igual a cinco. 
derando-se 25 observações, os valores críticos de $\tau_{\beta \tau}$ de Dickey e Fuller (1981) a 1\% e 5\% de nível de significância são, respectivamente, 3,74 e 2,85. Assim, é possível rejeitar a hipótese nula de que $a_{2}=0$.

Para se testar a hipótese nula $a_{0}=a_{2}=\gamma=0$, a estatística proposta é $\Phi_{2}$. Se o modelo irrestrito é dado pela regressão com constante e tendência e o modelo restrito é aquele sem tendência e constante, a estatística $\Phi_{2}$ é:

$$
\Phi_{2}=\frac{(9,834281-4,799097) / 3}{4,799097 / 23}=8,04
$$

onde 3 é o número de restrições e 23(=29-6) é o número de graus de liberdade no modelo sem restrições. Para 25 observações, os valores críticos de $\Phi_{2}$ a 2,5 e 5\% de nível de significância são, respectivamente, 6,75 e 5,68. Portanto, pode-se rejeitar a hipótese nula de que $\mathrm{a}_{\mathrm{o}}=\mathrm{a}_{2}=\gamma=0$. Isto significa que ao menos um desses parâmetros não é igual a zero, portanto, os dados contêm um intercepto e/ou uma raiz unitária e/ou uma tendência temporal.

Para se testar a hipótese nula $a_{2}=\gamma=0$, a estatística proposta é $\Phi_{3}$. Se modelo irrestrito é dado pela regressão com tendência e constante e o modelo restrito é aquele com constante e sem tendência lienar, a estatística $\Phi_{3}$ é:

$$
\Phi_{3}=\frac{(8,306341-4,799097) / 2}{4,799097 / 3}=8,4
$$

onde 2 é o número de restrições e 23(=29-6) é o número de graus de liberdade no modelo sem restrições. Para 25 observações, os valores críticos de $\Phi_{3}$ a $5 \%$ e $10 \%$ de nível de significância são, respectivamente, 7,24 e 5,91. Portanto, pode-se rejeitar a hipótese nula de que $a_{2}=\gamma=0$. Isso significa que os dados apresentam uma raiz unitária e/ou uma tendência linear.

Quanto à possibilidade de que a série da carga tributária tenha ordem de integração maior do que um e, por conseguinte, mais de uma raiz unitária, realizou-se o teste no qual a hipótese nula é de que a série em primeira diferença tem raiz unitária. O resultado do teste de Dickey-Fuller aumentado é o seguinte: ${ }^{14}$

$$
\begin{aligned}
& \Delta^{2} \tau_{t}=\underset{(-2,726965)}{-0,756100}+\underset{(2,817733)}{0,039294} t-\underset{(-7,119338)}{2,59608} \Delta \tau_{t-1} \\
& +\underset{(4,230547)}{1,099612} \Delta^{2} \tau_{t-1}+\underset{(3,324134)}{0,5553145 \Delta^{2} \tau_{t-2}}
\end{aligned}
$$

A estatística de Dickey-Fuller é -7,119338 e os valores críticos de Mackinnon a 1, 5 e $10 \%$ de nível de significância são, respectivamente, -4,3082, -3,5731 e -3,2203. Portanto, a hipótese nula de que há raiz unitária em primeira diferença é rejeitada, o que implica que a carga tributária é integrada de ordem um, I(1).

Com a amostra pequena que se tem em mãos, considerando-se os testes realizados e os critérios de Akaike e Schwartz, o modelo que inclui uma tendência linear e um drift parece ser o que melhor se ajusta aos dados da carga tributária no caso do Estado do Rio Grande do Sul. Portanto, a carga tributária não segue um passeio aleatório puro, o que contraria a teoria de Barro. Assim, há mais evidências de que a hipótese de estabilização da carga tributária deve ser rejeitada para o caso em estudo. ${ }^{15}$

14 Para a escolha do número de defasagens, adotou-se o procedimento de Campbell e Perron (1991).

15 Tanto Roubini e Sachs (1989) como Rocha (2001) rejeitam a hipótese de estabilização da carga tributária nos estudos de casos por eles pesquisados. 
A fim de se reforçarem as evidências pela rejeição da hipótese de carga tributária estável, adota-se a estratégia de Huang e Lin (1993) e Ghosh (1995). ${ }^{16}$ Segundo esses autores, o método indicado para se testar a validade da hipótese de carga tributária estável é o modelo de vetores auto-regressivos, o VAR. As vantagens de se utilizar esse método podem ser assim resumidas: i) a experiência econométrica com séries não-estacionárias sugere que é muito difícil determinar se uma determinada série de fato segue um passeio aleatório; ii) a hipótese de estabilidade da carga tributária é apenas uma entre as possíveis explicações de que a carga tributária segue um passeio aleatório; além disso, dependendo do processo seguido pelo PIB, visar reduzir os custos de distorção, estabilizando a carga tributária, não implica, necessariamente, que a carga segue um passeio aleatório; iii) informação importante é perdida quando o foco é sobre se a primeira diferença da carga é estacionária e não sobre se o nível é estacionário.

A Tabela 3 apresenta as estatísticas do teste ADF sobre a despesa total menos o serviço da dívida/PIB, $g_{t}$, a despesa total/PIB, $g_{t}{ }^{*}$, a receita tributária/PIB, $\tau_{t}$, e o superávit público/PIB, $\sup _{t}$. Ressalva-se que o superávit público é medido pela variação da relação dívida mobiliária/PIB, $b_{t}$. A análise do modelo VAR restringe-se ao intervalo 1970 a 1997 porque, a partir do ano de 1998, no bojo de um acordo de renegociação da dívida estadual com a União, o Estado do Rio Grande do Sul ficou proibido de emitir títulos da dívida para o público, exceto para pagamento de precatórios. ${ }^{17}$

Tabela 3 - Testes de raiz unitária Dickey-Fuller aumentado ${ }^{18}$

\begin{tabular}{lrrrr}
\hline & \multicolumn{1}{c}{$g_{t}$} & \multicolumn{1}{c}{${ }_{\mathrm{t}}{ }^{*}$} & \multicolumn{1}{c}{$\tau_{\mathrm{t}}$} & $\sup _{t}$ \\
\hline Estatística de Dickey-Fuller & $-3,089497$ & $-3,463560$ & $-3,347552$ & $-6,407579$ \\
Valores críticos de Mackinnon & & & & \\
$1 \%$ & $-4,3382$ & $-4,3382$ & $-4,3942$ & $-2,6560$ \\
$5 \%$ & $-3,5867$ & $-3,5867$ & $-3,6118$ & $-1,9546$ \\
$10 \%$ & $-3,2279$ & $-3,2279$ & $-3,2418$ & $-1,6226$ \\
$P$ & 0 & 0 & 3 & 0 \\
$\mathrm{~N}$ & 27 & 27 & 24 & 26 \\
\hline
\end{tabular}

Notas: 1) o número de defasagens foi escolhido de acordo com o procedimento de Campbell e Perron (1991); 2) para $g, g^{*} \mathrm{e}$ $\tau$ incluem-se uma constante e uma tendência linear; 3) os testes de presença de duas raízes unitárias, não apresentados aqui, rejeitaram a hipótese nula para as três séries; 4) para sup, a especificação sem constante e tendência foi a escolhida, considerando-se os critérios de Akaike e Schwartz; 5) as fontes dos dados são as Tabelas 7, 9 e 10 do Anexo.

Portanto, em relação a $g_{t}$, não se rejeita a hipótese nula de não estacionariedade aos três níveis de significância. Por outro lado, no caso de $\sup _{t}$, a hipótese nula de presença de uma raiz unitária é rejeitada nos três níveis.

Rodando-se a regressão da despesa total, $g_{t}^{*}$, sobre a carga tributária, $\tau_{t}$, estimou-se o parâmetro tax-tilting $(1 / \theta)$ igual a 1,622 (desvio padrão=0,055). Conforme o teste de Wald, o coeficiente estimado é significativamente diferente de um, o que significa a existência de um motivo tax-tilting na política de déficits públicos do governo estadual, indicando inconsistência com o modelo teórico.

16 Huang e Lin (1993) linearizam o modelo tax-smoothing em termos de log. Segundo eles, a abordagem empírica de Barro (1979, 1984), de decompor os gastos do governo e o produto em duas partes, uma permanente e outra temporária, tem, entre outras, a seguinte desvantagem: a validade dos resultados empíricos depende da especificação das variáveis e equações na construção dos componentes temporário ou permanente das séries. Mais detalhes sobre as desvantagens dos procedimentos de Barro (1979,1984), ver em Huang e Lin (1993).

17 Há um conjunto de estudos que analisam detalhadamente o histórico das negociações entre os Estados e a União até culminar na lei 9.496/97, que estabeleceu os critérios de renegociação das dívidas estaduais. Entre os estudos, pode-se citar Almeida (1996), Rigolon e Giambiagi (1999), Bevilaqua (1999) e Botelho (2002). No caso específico do Rio Grande do Sul, ver Santos e Calazans (1999).

18 Nos testes realizados, o número inicial de termos defasados foi igual a cinco. 
Na comparação do VAR de primeira, segunda e terceira ordens, não apresentada aqui, a defasagem ótima, observando-se o critério de Schwarz, é igual a um. A Tabela 4 apresenta os coeficientes do VAR de primeira ordem. Na equação para $\Delta g_{t}$, o coeficiente de $\sup _{t-1}$ não é estatisticamente significativo, ou seja, $\sup _{t}$ não causa $\Delta g_{t}$ no sentido de Granger. Portanto, os dados são inconsistentes com a implicação mais básica do modelo de estabilização da carga tributária.

Tabela 4 - Coeficientes do VAR

\begin{tabular}{lcc}
\hline & $\Delta g_{t}$ & $\sup _{t}$ \\
\hline$\Delta g_{t-1}$ & $-0,103440$ & $-0,378040$ \\
& $(0,227193)$ & $(0,682525)$ \\
$\sup _{t-1}$ & 0,092237 & $-0,272479$ \\
& $(0,087851)$ & $(0,281050)$ \\
\hline
\end{tabular}

Nota: desvio padrão consistente/heteroscedasticidade White entre parênteses.

$\mathrm{Na}$ análise teórica viu-se que, se a hipótese nula é correta, o coeficiente $\lambda_{1}$ deve ser igual a zero e o coeficiente $\lambda_{2}$ deve ser igual a $1 .{ }^{19}$ Os coeficientes estimados de $\Lambda, \lambda_{1}$ e $\lambda_{2}$ encontram-se na Tabela 5. Para o caso do Rio Grande do Sul, aplicando-se o teste de Wald, a hipótese nula é rejeitada, isto é, o coeficiente $\lambda_{1}$ estimado, 0,07 , é significativamente diferente de zero e o coeficiente $\lambda_{2}$ estimado, -0,008, é significativamente diferente de um. Assim, reforça-se a rejeição do modelo no caso em estudo.

Tabela 5 - Coeficientes de $\Lambda$

\begin{tabular}{cc}
\hline$\lambda_{1}$ & $\lambda_{2}$ \\
\hline 0,07 & $-0,008$ \\
$(0,05)$ & $(0,016)$ \\
\hline
\end{tabular}

Notas: 1) desvio padrão consistente/heteroscedasticidade de White entre parênteses; 2) Hipótese nula: $\lambda_{1}=0, \lambda_{2}=1$.

Portanto, a hipótese nula de estabilização da carga tributária não é correta no caso em estudo.

A partir do Gráfico 3, destacam-se os seguintes pontos: 1) em diversos anos há uma discrepância entre o superávit observado, $\sup _{t}$, e o superávit teórico, $\left.\sup _{t}^{*} ; 2\right)$ tais discrepâncias são maiores no período pós-1987; 3) entre 1970 e 1987, o ótimo seria um equilíbrio entre receitas e despesas, no entanto, nos anos 1974, 1975, 1981 e 1982, são gerados superávits públicos; 4) após 1987, os déficits públicos teóricos ocorrem em 1991 e 1995, enquanto os observados surgem em 1990 e 1994. Tais diferenças de comportamento indicam ausência de evidências que sustentem a hipótese de carga tributária estável no caso em estudo.

19 Isso equivale a uma condição simples sobre a matriz de transição do VAR, A. Dado que $\sup _{t}^{*}=[10] R A[I-R A]^{-1} z_{t} \mathrm{e}$ $\sup _{\mathrm{t}}=[01] \mathrm{z}_{\mathrm{t}}, \sup _{\mathrm{t}}{ }^{*}=\sup _{\mathrm{t}}$ se $[10] R A[I-R A]^{-1}=[01]$. Pós-multiplicando o lado direito desta igualdade por [I-RA] e adicionando-se [01]RA, tem-se: [10]RA $+[01] R A=[11] R A$. Supondo-se $R=1,[11] \mathrm{A}=[01]$ se a soma dos elementos da primeira coluna de $A, a+a$, é igual a zero e a soma dos elementos da segunda coluna de $A, a+a$, é igual a 1. Calculou-se a taxa de juros real como $r_{t}=\left[\left(1+i_{\mathrm{t}}\right) /(1+\pi)\right]-1$, onde $\mathrm{i}_{\mathrm{t}}$ é taxa de juros nominal no ano $\mathrm{t}$ (medida pela relação pagamento de juros/dívida pública total) e $\pi_{t}$ a taxa de inflação anual (medida pelo IGP-DI). Considerando-se $\mathrm{n}$ igual à taxa de crescimento do produto real média e $\mathrm{r}$ a taxa de juros real média do período 1970-1997, concluiu-se que $R=(1+n) /(1+r)$ é aproximadamente igual a um. 


\section{Gráfico 3 - Evolução do superávit público observado e do superávit ótimo (1971-1997)}

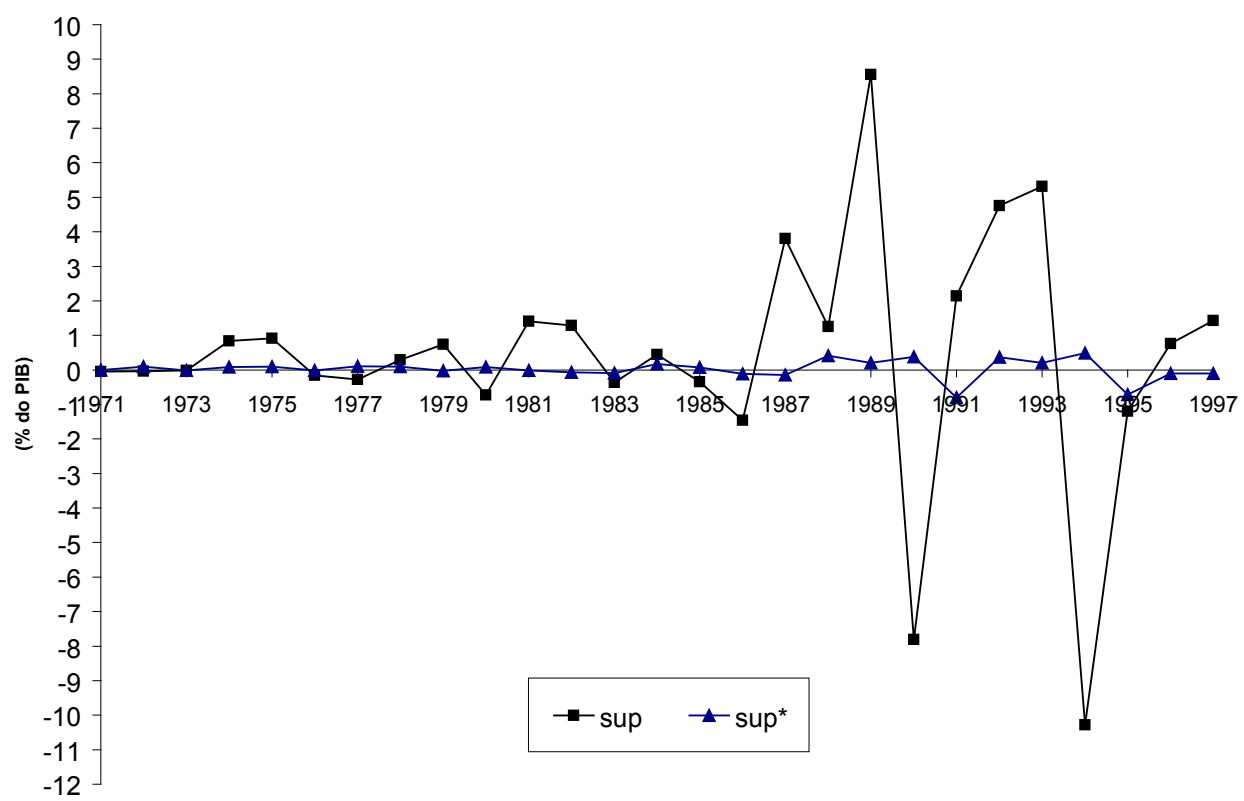

Fonte: Tabela 9 do Anexo.

Os coeficientes de correlação e as relações entre os desvios padrões das duas séries, $\sup _{\mathrm{t}} \mathrm{e}$ $\sup _{t}{ }^{*}$, sintetizam a relação entre o superávit teórico e o superávit observado. Na Tabela 6, as correlações entre as duas séries são negativas nos períodos 1970-1997 e 1987-1997. Além disso, em ambos os intervalos de tempo, a relação entre os desvios padrões é superior a 12; portanto, os movimentos de $\sup _{t}$ não seguem os movimentos de $\sup _{t}{ }^{*}$. Tais indicadores reforçam os indícios de que o governo estadual não buscou minimizar os custos de distorção. Contudo, no período 1970-1986, desconsiderando as diferenças de magnitudes, as duas séries são positivamente correlacionadas, isto é, nesse período, o modelo de estabilização da carga tributária explica melhor os movimentos do superávit público observado.

Tabela 6 - Estatísticas que resumem a relação sup e sup*

\begin{tabular}{lcccc}
\hline Período & $\sigma\left(\sup _{t}\right)$ & $\sigma\left(\sup _{t}{ }^{*}\right)$ & $\sigma\left(\sup _{t}\right) / \sigma\left(\sup _{t}{ }^{*}\right)$ & Corr $\left(\sup _{t}, \sup _{t}{ }^{*}\right)$ \\
\hline $1970-1997$ & 3,51 & 0,28 & 12,54 & $-0,18070$ \\
$1970-1986$ & 0,76 & 0,08 & 9,50 & 0,14677 \\
$1987-1997$ & 5,55 & 0,44 & 12,61 & $-0,19212$ \\
\hline
\end{tabular}

\section{CONSIDERAÇÕES FINAIS}

No caso do Estado do Rio Grande do Sul, as primeiras evidências, para o período 1970 a 2002, indicaram a rejeição da hipótese de estabilização da carga tributária: a) a relação dívida pública/ 
PIB não segue o padrão proposto pela teoria, e b) o modelo que parece se ajustar melhor aos dados da carga tributária é o que apresenta uma tendência linear e um termo drift.

À luz da estratégia de Ghosh (1995), novamente as evidências, para o intervalo de 1970 a 1997, são pela rejeição da hipótese. Em primeiro lugar, detectou-se a existência de um motivo tax-tilting na política de déficits públicos do governo estadual; em segundo, o superávit orçamentário não causa (no sentido de Granger) uma mudança nos gastos do governo estadual; em terceiro, as restrições sobre os coeficientes de $\sup _{t}$ e $\Delta g_{t}$ não foram observadas; em quarto e último lugar, não houve correspondência entre os superávits observados e os teóricos. Em suma, o governo do Estado do Rio Grande do Sul não levou a cabo uma política fiscal que visasse minimizar os custos de distorção provocados pela elevação de impostos, isto é, não se comportou como um tax-smoother.

O modelo de estabilização da carga tributária não explica os constantes déficits públicos gerados pelos sucessivos governos do Estado do Rio Grande do Sul ao longo das décadas de 1970, 1980 e 1990. O máximo que faz é justificar os déficits públicos afirmando que os governantes não são "planejadores benevolentes" ou, então, adotam comportamentos irracionais na condução da política fiscal. Tal resultado indica que a busca por uma teoria positiva para a geração de déficits públicos no caso em questão deve se concentrar em outra linha de pesquisa - uma candidata é a linha que enfatiza os conflitos de interesses entre grupos e a heterogeneidade de interesses como explicações para os constantes déficits públicos.

\section{REFERÊNCIAS BIBLIOGRÁFICAS}

Almeida, Anna Ozorio de. Evolução e crise da dívida pública estadual. Texto para Discussão n. 448. IPEA, nov. 1996.

Balanço Geral do Estado do Rio Grande Do Sul [dados informativos on-line]. Porto Alegre, 2003. Disponível em: <http://www.sefaz.rs.gov. br>.

Barro, Robert J. On the determination of public debt. Journal of Political Economy, v. 87, n. 5, p. 940-71, 1979.

Barro, Robert J. Federal deficit policy and the effects of public debt schocks. National Bureau of Economic Research Working Paper Series, Working Paper n. 443, Feb. 1980.

Barro, Robert J. The behavior of US deficits. National Bureau of Economic Research Working Paper Series, Working Paper n. 1309, Mar. 1984.

Barro, Robert J. The neoclassical approach to fiscal policy. In: BARRO, Robert J., (ed.), Modern Business Cycle Theory. Cambridge: Harvard University Press. 1989a.

Barro, Robert J. The ricardian approach to budget deficits. Journal of Economic Perspectives, v. 3, n. 2, p. 37-54, 1989b.

Barro, Robert J. Macroeconomics. Cambridge: The MIT Press. $5^{\text {a }}$ ed. 1997.

Bevilaqua, Afonso S. State-government bailouts in Brazil. Departamento de Economia da PUC-Rio. Draft, May 1999.

Bordin, Luís Carlos Vitali. Carga tributária brasileira em 2002. Estudos Econômicos-Fiscais. Porto Alegre, ano 9, n. 35, fev. 2003.

Botelho, Ricardo. Determinantes do ajuste fiscal dos estados brasileiros. Finanças Públicas: IV Prêmio Tesouro Nacional - coletânea de monografias, Brasília: ESAF, 2002.

Enders, Walter. Applied econometric time series. John Wiley \& Sons, Inc.,1995.

Finanças Públicas [on-line]. Porto Alegre, 2003. Disponível em: <http://www.sefaz.rs.gov. br>. 
Ghosh, Atish R. Intertemporal Tax-smoothing and the government budget surplus: Canada and the United States. Journal of Money, Credit, and Banking, v. .27, n. 4, p. 1033-45, Nov., 1995.

Huang, Chao-Hsi; LIN, Kenneth S. Deficits, government expenditures, and tax smoothing in the United States: 1929-1988. Journal of Monetary Economics, 31, p. 317-339. 1993.

Pastore, Affonso Celso. Déficit público, a sustentabilidade do crescimento das dívidas interna e externa, senhoriagem e inflação: uma análise do regime monetário brasileiro. Revista de Econometria, v. 14, n. 2, p. 177-234, nov. 1994-dez.1995, 1995.

Pereira, Rodrigo M. Demanda Dinâmica por emprego e horas e a questão da partilha de trabalho: aplicações do modelo linear-quadrático. Dissertação (Mestrado) - Departamento de Economia da Pontifícia Universidade Católica, Rio de Janeiro, 1998.

Rigolon, Francisco; Giambiagi, Fabio. A renegociação das dívidas e o regime fiscal dos Estados. In: Giambiagi, Fabio; Moreira, Mauricio Mesquita (org.) A economia brasileira nos anos 90. Rio de Janeiro: BNDES, 1999.

Rocha, Fabiana. Is there any rationale to the Brazilian fiscal policy? Revista Brasileira de Economia, v. 55, n. 3, p. 315-331, jul.-set. 2001.

Romer, David. Advanced macroeconomics. $2^{\text {a }}$ ed. McGraw-Hill, 2001.

Roubini, Nouriel; Sachs, Jeffrey D. Political and economic determinants of budget deficits in the industrial democracies. European Economic Review, v. 33, p. 903-38, 1989.

Santos, Darcy F. C. dos; Calazans, Roberto B. A crise da dívida pública do RS - Fundamentos, evolução e perspectivas/1970-1998. Porto Alegre: Assembléia Legislativa do Estado do Rio Grande do Sul (Comissão de Finanças e Planejamento), nov. 1999.

Schwengber, Silvane B.; Ribeiro, Eduardo Pontual. O impacto do Fundo de Participação (FPE) no esforço tributário dos Estados: uma estimativa do potencial de arrecadação do ICMS. Finanças Públicas: IV Prêmio Tesouro Nacional - coletânea de monografias, Brasília: ESAF, 2000. 


\section{ANEXO}

Tabela 7 - Receita tributária (Administração Direta), PIB do Rio Grande do Sul e carga tributária (1970-02)

\begin{tabular}{|c|c|c|c|}
\hline ANOS & $\begin{array}{l}\text { RECEITA TRIBUTÁRIA } \\
(\mathrm{R} \$)\end{array}$ & $\begin{array}{l}\mathrm{PIB}^{2} \\
(\mathrm{R} \$)\end{array}$ & $\begin{array}{c}\text { CARGA TRIBUTÁRIA }=\tau_{t} \\
(\%)\end{array}$ \\
\hline 1970 & 0,0004293582 & 0,0053127273 & 8,08 \\
\hline 1971 & 0,0005922825 & 0,0072254545 & 8,20 \\
\hline 1972 & 0,0007303844 & 0,0094036364 & 7,77 \\
\hline 1973 & 0,0009963447 & 0,0146036364 & 6,82 \\
\hline 1974 & 0,0013302593 & 0,0208254545 & 6,39 \\
\hline 1975 & 0,0019207102 & 0,0291345455 & 6,59 \\
\hline 1976 & 0,0025416233 & 0,0454654545 & 5,59 \\
\hline 1977 & 0,0040293313 & 0,0683200000 & 5,90 \\
\hline 1978 & 0,0055776222 & 0,0989090909 & 5,64 \\
\hline 1979 & 0,0087595018 & 0,1600290909 & 5,47 \\
\hline 1980 & 0,0187360804 & 0,3426581818 & 5,47 \\
\hline 1981 & 0,0403135880 & 0,6697418182 & 6,02 \\
\hline 1982 & 0,0834082844 & 1,2926581818 & 6,45 \\
\hline 1983 & 0,1864809782 & 3,4141490909 & 5,46 \\
\hline 1984 & 0,6008701935 & 10,9621672727 & 5,48 \\
\hline 1985 & 2 & 38 & 5,26 \\
\hline 1986 & 7 & 101 & 6,93 \\
\hline 1987 & 18 & 317 & 5,68 \\
\hline 1988 & 123 & 2.462 & 5,00 \\
\hline 1989 & 2.223 & 37.598 & 5,91 \\
\hline 1990 & 69.117 & $939.363,40$ & 7,36 \\
\hline 1991 & 313.778 & $4.666 .959,02$ & 6,72 \\
\hline 1992 & 3.403 .833 & $54.964 .960,58$ & 6,19 \\
\hline 1993 & 72.389 .398 & 1.260 .808 .219 & 5,74 \\
\hline 1994 & 2.155 .483 .151 & 31.129 .234 .457 & 6,92 \\
\hline 1995 & 3.631 .675 .187 & 53.652 .946 .828 & 6,77 \\
\hline 1996 & 4.194 .757 .608 & 63.262 .677 .227 & 6,63 \\
\hline 1997 & 4.237 .215 .255 & 69.221 .313 .934 & 6,12 \\
\hline 1998 & 4.515.641.472 & 70.541 .889 .405 & 6,40 \\
\hline 1999 & 4.941.505.295 & 75.450 .458 .225 & 6,55 \\
\hline 2000 & 5.960 .206 .517 & 85.137 .542 .554 & 7,00 \\
\hline 2001 & 7.138.685.853 & 97.310 .194 .511 & 7,34 \\
\hline 2002 & 7.808.523.095 & 109.742 .129 .654 & 7,12 \\
\hline
\end{tabular}

Fontes: 1) Finanças do Estado e Finanças Públicas on-line. Porto Alegre: Secretaria da Fazenda. 2) FEE (Núcleo de Contas Regionais).

Notas: i) a preços correntes; ii) os dados do PIB de 2000 a 2002 são preliminares; iii) carga tributária=receita tributária/ $\mathrm{PIB}=\tau_{t}$. 
Tabela 8 - Dívida pública (Administração Direta), PIB do Rio Grande do Sul e a relação dívida pública/PIB (1970-02)

\begin{tabular}{|c|c|c|c|}
\hline ANOS & $\begin{array}{c}\text { DíVIDA PÚBLICA }{ }^{1} \\
\mathrm{R} \$\end{array}$ & $\begin{array}{l}\mathrm{PIB}^{2} \\
\mathrm{R} \$\end{array}$ & $\begin{array}{c}\text { divida/PIB } \\
(\%)\end{array}$ \\
\hline 1970 & 0,0003284873 & 0,0053127273 & 6,18 \\
\hline 1971 & 0,0003654109 & 0,0072254545 & 5,06 \\
\hline 1972 & 0,0004281018 & 0,0094036364 & 4,55 \\
\hline 1973 & 0,0006134655 & 0,0146036364 & 4,20 \\
\hline 1974 & 0,0009144473 & 0,0208254545 & 4,39 \\
\hline 1975 & 0,0014304109 & 0,0291345455 & 4,91 \\
\hline 1976 & 0,0026616982 & 0,0454654545 & 5,85 \\
\hline 1977 & 0,0036458982 & 0,0683200000 & 5,34 \\
\hline 1978 & 0,0057811491 & 0,0989090909 & 5,84 \\
\hline 1979 & 0,0106532218 & 0,1600290909 & 6,66 \\
\hline 1980 & 0,0175670691 & 0,3426581818 & 5,13 \\
\hline 1981 & 0,0468441018 & 0,6697418182 & 6,99 \\
\hline 1982 & 0,1282316873 & 1,29 & 9,94 \\
\hline 1983 & 0,4047090909 & 3,41 & 11,87 \\
\hline 1984 & 1,57 & 10,96 & 14,32 \\
\hline 1985 & 6,01 & 38,41 & 15,65 \\
\hline 1986 & 10,67 & 100,78 & 10,59 \\
\hline 1987 & 55,08 & 316,51 & 17,40 \\
\hline 1988 & 516,73 & $2.461,90$ & 20,99 \\
\hline 1989 & $9.889,87$ & $37.598,05$ & 26,30 \\
\hline 1990 & $156.633,62$ & $939.363,36$ & 16,67 \\
\hline 1991 & $891.816,27$ & $4.666 .959,96$ & 19,11 \\
\hline 1992 & $13.392 .938,06$ & $54.964 .960,96$ & 24,37 \\
\hline 1993 & $378.029 .161,29$ & $1.260 .808 .219,27$ & 29,98 \\
\hline 1994 & $4.766 .006 .840,76$ & $31.129 .234 .456,59$ & 15,31 \\
\hline 1995 & $8.072 .969 .953,52$ & $53.652 .946 .827,60$ & 15,05 \\
\hline 1996 & $10.465 .094 .737,38$ & $63.262 .677 .226,56$ & 16,54 \\
\hline 1997 & $13.538 .891 .837,06$ & $69.221 .313 .934,13$ & 19,56 \\
\hline 1998 & $14.822 .676 .951,74$ & $70.541 .889 .405,25$ & 21,01 \\
\hline 1999 & $17.564 .387 .092,30$ & $75.450 .458 .225,36$ & 23,28 \\
\hline 2000 & $20.276 .454 .008,02$ & $85.137 .542 .554,42$ & 23,82 \\
\hline 2001 & 23.662.809.978,47 & $97.310 .194 .511,19$ & 24,32 \\
\hline 2002 & $28.470 .330 .925,46$ & $109.742 .129 .653,58$ & 25,94 \\
\hline
\end{tabular}

Fontes: 1) Balanço Geral do Estado do Rio Grande do Sul (1970-2002). Porto Alegre: Secretaria da Fazenda. 2) FEE (Núcleo de Contas Regionais).

Notas: 1) os dados do PIB de 2000 a 2002 são preliminares; 2) a preços correntes; 3) a dívida pública = dívida fundada + dívida flutuante. 
Tabela 9 - Dívida mobiliária, superávits teórico e observado da Administração Direta (1970-97)

\begin{tabular}{|c|c|c|c|c|c|}
\hline ANOS & $\begin{array}{l}\text { DÍVIDA MOBILIÁRIA }^{1} \\
\text { R\$ }\end{array}$ & $\begin{array}{l}\mathrm{PIB}^{2} \\
\mathrm{R} \$\end{array}$ & $\begin{array}{c}b_{t} \\
(\%)\end{array}$ & $\sup _{t}$ & $\sup _{t}^{*}$ \\
\hline 1970 & 0,0000290909 & 0,0053127273 & 0,55 & & \\
\hline 1971 & 0,0000363636 & 0,0072254545 & 0,50 & $-0,05$ & 0,00 \\
\hline 1972 & 0,0000436364 & 0,0094036364 & 0,46 & $-0,04$ & 0,09 \\
\hline 1973 & 0,0000654545 & 0,0146036364 & 0,45 & $-0,01$ & $-0,02$ \\
\hline 1974 & 0,0002690909 & 0,0208254545 & 1,29 & 0,84 & 0,08 \\
\hline 1975 & 0,0006436364 & 0,0291345455 & 2,21 & 0,92 & 0,09 \\
\hline 1976 & 0,0009309091 & 0,0454654545 & 2,05 & $-0,16$ & $-0,01$ \\
\hline 1977 & 0,0012109091 & 0,0683200000 & 1,77 & $-0,28$ & 0,11 \\
\hline 1978 & 0,0020327273 & 0,0989090909 & 2,06 & 0,29 & 0,09 \\
\hline 1979 & 0,0044763636 & 0,1600290909 & 2,80 & 0,74 & $-0,03$ \\
\hline 1980 & 0,0070836364 & 0,3426581818 & 2,07 & $-0,73$ & 0,08 \\
\hline 1981 & 0,0233018182 & 0,6697418182 & 3,48 & 1,41 & $-0,01$ \\
\hline 1982 & 0,0614981818 & 1,29 & 4,77 & 1,29 & $-0,07$ \\
\hline 1983 & 0,15 & 3,41 & 4,40 & $-0,37$ & $-0,09$ \\
\hline 1984 & 0,53 & 10,96 & 4,84 & 0,44 & 0,17 \\
\hline 1985 & 1,73 & 38,41 & 4,50 & $-0,34$ & 0,07 \\
\hline 1986 & 3,06 & 100,78 & 3,04 & $-1,46$ & $-0,11$ \\
\hline 1987 & 21,64 & 316,51 & 6,84 & 3,80 & $-0,15$ \\
\hline 1988 & 199,34 & $2.461,90$ & 8,10 & 1,26 & 0,41 \\
\hline 1989 & $6.260,62$ & $37.598,05$ & 16,65 & 8,55 & 0,20 \\
\hline 1990 & $83.011,22$ & $939.363,36$ & 8,84 & $-7,81$ & 0,38 \\
\hline 1991 & $512.407,86$ & $4.666 .959,96$ & 10,98 & 2,14 & $-0,80$ \\
\hline 1992 & $8.650 .362,04$ & $54.964 .960,96$ & 15,74 & 4,76 & 0,37 \\
\hline 1993 & $265.532 .290,85$ & $1.260 .808 .219,27$ & 21,06 & 5,32 & 0,20 \\
\hline 1994 & $3.354 .475 .351,21$ & $31.129 .234 .456,59$ & 10,78 & $-10,28$ & 0,49 \\
\hline 1995 & $5.137 .866 .177,54$ & $53.652 .946 .827,60$ & 9,58 & $-1,20$ & $-0,72$ \\
\hline 1996 & $6.543 .120 .901,15$ & $63.262 .677 .226,56$ & 10,34 & 0,76 & $-0,10$ \\
\hline 1997 & $8.144 .172 .567,80$ & $69.221 .313 .934,13$ & 11,77 & 1,43 & $-0,10$ \\
\hline
\end{tabular}

Fontes: 1) Balanço Geral do Estado do Rio Grande do Sul (1970-2002). Porto Alegre: Secretaria da Fazenda. 2) FEE (Núcleo de Contas Regionais).

Notas: i) a preços correntes; ii) dívida mobiliária $=$ dívida fundada interna em títulos; iii) superávit observado, $\sup _{t}=\Delta b_{t}$, onde $b$ é a dívida mobiliária estadual; iv) supondo-se $R=1$, o superávit teórico é dado pela equação (13) no texto. 
Tabela 10 - Evolução de $g_{t}$ e $g_{t}^{*}$ da Administração Direta do Estado do Rio Grande do Sul (1970-97)

\begin{tabular}{|c|c|c|c|c|c|}
\hline ANOS & $\begin{array}{c}\text { DT-SD } \\
\text { R\$ }\end{array}$ & $\begin{array}{c}\mathrm{PIB}^{2} \\
\mathrm{R} \$\end{array}$ & $\begin{array}{c}g_{t} \\
(\%)\end{array}$ & $\begin{array}{l}\mathrm{DT}^{1} \\
\mathrm{R} \$\end{array}$ & $\begin{array}{l}g_{t}^{*} \\
(\%)\end{array}$ \\
\hline 1970 & 0,0005446611 & 0,0053127273 & 10,25 & 0,000565925 & 10,65 \\
\hline 1971 & 0,0006808375 & 0,0072254545 & 9,42 & 0,000711944 & 9,85 \\
\hline 1972 & 0,0009018695 & 0,0094036364 & 9,59 & 0,000937672 & 9,97 \\
\hline 1973 & 0,0012945957 & 0,0146036364 & 8,86 & 0,001335484 & 9,14 \\
\hline 1974 & 0,0017727778 & 0,0208254545 & 8,51 & 0,001860253 & 8,93 \\
\hline 1975 & 0,0026582393 & 0,0291345455 & 9,12 & 0,002893229 & 9,93 \\
\hline 1976 & 0,0036927415 & 0,0454654545 & 8,12 & 0,004035937 & 8,88 \\
\hline 1977 & 0,0049066276 & 0,0683200000 & 7,18 & 0,005575929 & 8,16 \\
\hline 1978 & 0,0075037516 & 0,0989090909 & 7,59 & 0,008330993 & 8,42 \\
\hline 1979 & 0,0116956065 & 0,1600290909 & 7,31 & 0,013449504 & 8,40 \\
\hline 1980 & 0,0239233054 & 0,3426581818 & 6,98 & 0,027583114 & 8,04 \\
\hline 1981 & 0,0562233207 & 0,6697418182 & 8,39 & 0,063326955 & 9,45 \\
\hline 1982 & 0,1277944273 & 1,29 & 9,91 & 0,149651869 & 11,60 \\
\hline 1983 & 0,2811111822 & 3,41 & 8,24 & 0,378290693 & 11,09 \\
\hline 1984 & 0,86 & 10,96 & 7,85 & 1,10 & 10,05 \\
\hline 1985 & 3,31 & 38,41 & 8,62 & 5,24 & 13,65 \\
\hline 1986 & 9,16 & 100,78 & 9,09 & 11,82 & 11,73 \\
\hline 1987 & 24,18 & 316,51 & 7,64 & 34,36 & 10,86 \\
\hline 1988 & 163,26 & $2.461,90$ & 6,63 & 227,24 & 9,23 \\
\hline 1989 & $3.042,89$ & $37.598,05$ & 8,09 & $3.381,70$ & 8,99 \\
\hline 1990 & $100.462,75$ & $939.363,36$ & 10,69 & $112.959,97$ & 12,02 \\
\hline 1991 & $404.276,14$ & $4.666 .959,96$ & 8,66 & $474.847,30$ & 10,17 \\
\hline 1992 & $5.250 .591,13$ & $54.964 .960,96$ & 9,55 & $6.376 .873,02$ & 11,60 \\
\hline 1993 & $104.164 .099,26$ & $1.260 .808 .219,27$ & 8,26 & $137.868 .403,92$ & 10,93 \\
\hline 1994 & $2.747 .296 .328,00$ & $31.129 .234 .456,59$ & 8,83 & $3.608 .445 .175,00$ & 11,59 \\
\hline 1995 & $4.854 .297 .768,00$ & $53.652 .946 .827,60$ & 9,05 & $6.103 .134 .908,00$ & 11,38 \\
\hline 1996 & $6.550 .116 .607,00$ & $63.262 .677 .226,56$ & 10,35 & $7.806 .427 .374,00$ & 12,34 \\
\hline 1997 & 7.409.530.180,00 & $69.221 .313 .934,13$ & 10,70 & $9.143 .412 .051,00$ & 13,21 \\
\hline
\end{tabular}

Fontes: 1) Balanço Geral do Estado do Rio Grande do Sul (1970-2002). Porto Alegre: Secretaria da Fazenda. 2) Fundação de Economia e Estatística.

Notas: i) a preços correntes; ii) DT-SD é a despesa total menos o serviço da dívida; ii) DT é a despesa total; iii) SD é o serviço da dívida; iv) $g^{*}=$ despesa total/PIB; v) DT-SD/PIB $=g_{t}$. 